\title{
Basic Electrical Parameters Measurement Laboratory: A K-12 Outreach Project
}

Dr. Rohit Dua, Missouri University of Science \& Technology

ROHIT DUA, Ph.D is an Associate Teaching Professor in the Department of Electrical and Computer Engineering at the Missouri University of Science and Technology and Missouri State University's Cooperative Engineering Program. His research interests include engineering education. (http://web.mst.edu/ rdua/) 


\title{
Basic Electrical Parameters Measurement Laboratory: A K-12 Outreach Project
}

\begin{abstract}
A basic laboratory exercise was designed and implemented, for K-12 students, which delves into the measurement of basics of electrical circuit parameters, such as resistance, current and voltage. This 2-3 hour lab exercise gives students a glimpse into basic electrical engineering concepts, which are covered in an undergraduate Sophomore level introductory Circuits-1 course that all Electrical Engineering majors are required to take. Laboratory participants cover the same material, in a small amount of time that the undergraduate students cover in 2-3 weeks. The lab exercise also includes an interactive exercise that helps students understand decimal to binary conversion for unsigned and signed decimal numbers via a tool already being used as part of interactive digital logic laboratory experience. In addition, students try their skill in generating power, under varying load conditions, using a bike-power generator as a fun-filled competitive activity. This paper outlines the laboratory exercise learning outcomes, implemented laboratory exercises, observations made, and results of a conducted exit survey.
\end{abstract}

\section{Introduction}

Sophomore level Electrical and Computer Engineering (ECE) courses consists of introductory circuits, digital logic and electronics courses. These courses cover the basics of the ECE field via thorough multiple lecture and laboratory courses. Students, taking these undergraduate courses, learn basic concepts through extensive mathematical treatment, varied examples and homework problems in addition to comprehensive laboratory experiments. Recent trend has focused on exposing K-12 students to engineering concepts through multitude of products and experimental modules [1]. Such experiences may or may not, depending on the product or exercise, concentrate on fundamentals of ECE concepts [1]. The goal of the developed and implemented laboratory module is to answer the following question: "How can we expose K-12 students to basic ECE concepts via interactive laboratory exercises?". Note that such concepts may or may not be covered in a K-12 academic setting. K-12 teachers may just cover rudimentary information on basic electrical concepts. The depth of the coverage may be sporadic from school-to-school. Major goals of this research are:

- To teach K-12 students concepts covered in Sophomore level ECE courses.

- To develop tools and educational modules that optimize learning of basic ECE concepts in a laboratory setting.

- To disseminate developed educational modules to upper elementary, middle and high schools students.

The designed and implemented laboratory not only provides hand-on experience in using basic DC electrical parameter instruments, including voltmeter, ammeter and ohmmeter, but also, delves into a discussion and understanding of basic theoretical concepts via multiple measurements. Moreover, exposure to additional interactive exercises to understand basic computer engineering concepts and mechanical power generation adds excitement and variety to the implemented laboratory. The laboratory has been implemented for upper elementary and middle school students in an informal setting without formal surveys and feedback. This paper concentrates on discussing the implementation for high school students enrolled in the GOCAPS program [2]. This progressive program provides high school students a unique and yearlong learning experience to explore future career options [2]. Participating schools in the 
Greater Ozarks area, in Missouri (USA), are allotted a number of seats in the program. Students from the participating schools apply for the GO-CAPS program in their choice of area. The GOCAPS board selects students based on the student's interest and willingness to engage in the program. The laboratory exercise was implemented for students enrolled in the 'Engineering and Manufacturing' area of the GO-CAPS program. A part of their year long experience was to explore the undergraduate ECE degree offered at the Missouri University of Science and Technology and Missouri State University's (MSU) Cooperative Engineering program, housed at MSU, which is located in the Ozarks. The developed and implemented laboratory exercise proved to be an ideal activity to expose high school students to ECE concepts. Note that the developed laboratory is not only meant for students enrolled in GO-CAPS program, but also for upper elementary, middle and other high school students.

The next section describes the implemented laboratory components and exercises. Examples of implemented laboratory follows the next section followed by results of a conducted exit survey. The paper concludes by discussing potential planned improvements for future laboratory sessions.

\section{Lab Description and Implementation}

The learning objectives outlined for the proposed research is vast and continually evolving. Covering all the considered engineering concepts will take multiple laboratory sessions. In order to accommodate GO-CAPS students only a subset of the considered learning objectives were implemented and include:

1. Understand how resistors are connected in series and parallel on a breadboard.

2. Develop skill in using an ohmmeter, voltmeter and ammeter to measure basic electrical parameters.

3. Investigate the applications of Kirchoff's voltage and current laws.

4. Assess the effect of connecting resistors in series and parallel on the overall resistance via electrical measurements.

5. Develop skill in converting positive and negative decimal integers into equivalent binary representation

6. Explore electrical power generation and usage via the bike power generator connected to variable light bulb loads.

The electrical parameters measurement exercises were designed to emphasize the following concepts in order:

- Use an ohmmeter to measure resistance of individual resistors, resistors connected in series and parallel

$\circ$ Understand how resistance changes when resistors are connected in series as compared to when resistors are connected in parallel.

- Use a voltmeter to measure the source voltage, and the voltage across individual resistors connected in a series circuit

- Verify Kirchhoff's Voltage Law (KVL) in the series circuit

$\bigcirc$ In addition, measurements must emphasize the following rule: When resistors are connected in a series circuit, the voltage across a particular resistor is directly proportional to its resistance value. 
- Use an ammeter to measure the source current and the current flowing through individual resistors connected in a parallel circuit.

$\circ$ Verify Kirchhoff's Current Law (KCL) in the parallel circuit

- In addition, measurements must emphasize the following rule: When resistors are connected in a parallel circuit, the current through a particular resistor is inversely proportional to its resistance value.

The practical study of Electrical Engineering concepts is generally carried out by building test circuits on a solderless breadboards and running measurement-based experiments. Therefore, the choice of using a breadboard as the platform for the planned experiments was obvious. Note, experience has shown that it takes some time, spanning over multiple laboratory sessions, for some undergraduate Electrical and Computer Engineering students to grasp the concept of creating working circuits on breadboards. Owing to limited available laboratory session time, the exercise of learning how to build circuits on breadboard was omitted. Though, a basic discussion of how resistors are connected, on a breadboard, was carried out at the beginning of the laboratory exercise. Figure 1 shows the circuit, on breadboard, which was used for the laboratory exercise.

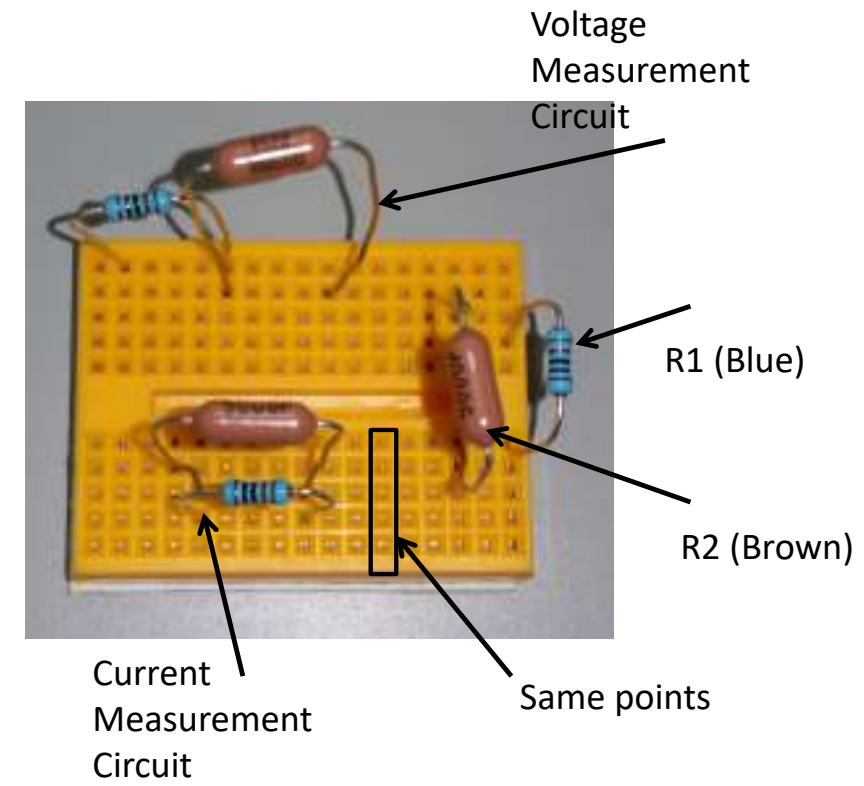

Figure 1: Circuit used for the laboratory exercise. The different circuits cover the different planned exercises. The resistors were color-coded for ease of visualization.

Two resistor values were chosen to keep the circuits and measurements simple. The resistors were color-coded. All resistors have a $1 \%$ tolerance value so that the measurements would be close to the expected values. $\mathrm{R} 1$, which is a $1 \mathrm{k} \Omega$ (blue color) resistor and $\mathrm{R} 2$, which is a $500 \Omega$ (brown color) resistor were used as seen in Figure 1. R1 and R2 are also connected in a series circuit, which is also used for voltage measurement. R1 and R2 are also connected in parallel circuit, which is also used for current measurement. After a brief discussion on the circuits and resistors, students attempted the first experiment, which is measuring resistance value. Each student was given the experimental procedures manual, which also served as a lab notebook to write the taken measurements, calculations and comments. In addition, each group 
was given a Digital Multi-Meter (DMM) and a variable DC power supply for the implemented exercises.

Students were shown the terminals used for measuring resistance, which are also used for measuring voltage. The measuring leads were color coated for ease of usage. A red lead was used for the positive terminal (+) and a black lead was used for the negative (-) terminal. First, students were asked to identify the stand-alone R1 (blue resistor) on the breadboard. Setting the DMM, on ohmmeter, students were instructed to connect the measurement leads across the resistor under test and observe the resistance value on the meter display. Visual aids, shown in Figure 2, helped students understand and make the connections for required measurements.
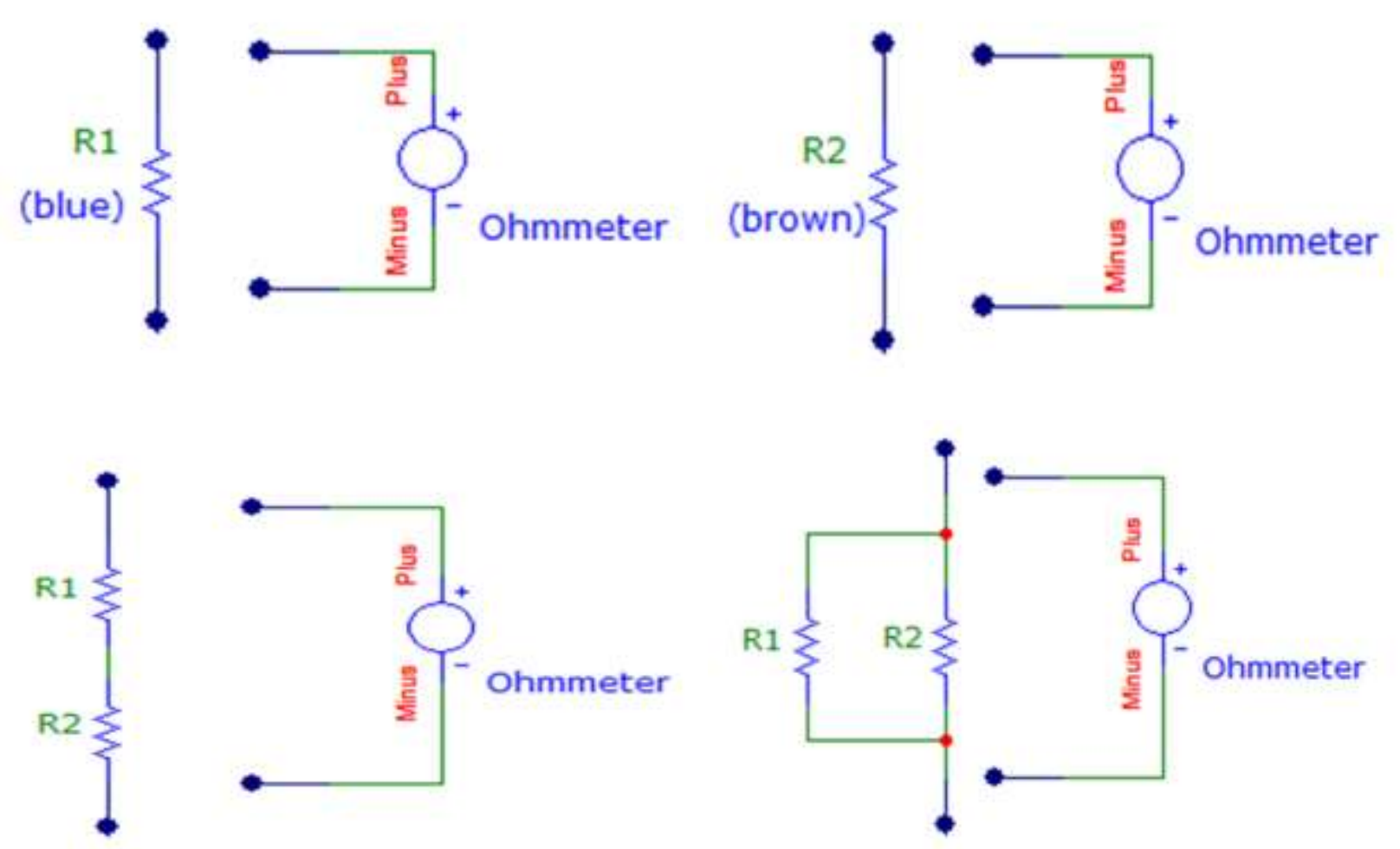

Figure 2: Circuit diagrams to aid the measurement of resistance using an ohmmeter. R1 and R2 are individual resistors. The circuit on the bottom left is the series resistance circuit, which is also used for voltage measurements. The circuit on the bottom right is the parallel resistance circuit, which is also used for current measurements.

Students were also asked to observe the effect on the resistance values, of individual resistors, if the leads labeled 'plus' (red) and 'minus' (black) were interchanged. Similarly, the resistance of R2, series resistance circuit and parallel resistance circuit were measured. As students made measurements for series and parallel resistance circuit, they were asked to draw conclusions on how the resistance changes when resistors are connected in series and in parallel. Students were asked to relate the measured resistance values to the individual resistor values. Suitable equations were given to provide mathematical reasoning to the observed measured values.

The next laboratory exercise concentrated on measuring voltages. For this exercise the series resistance circuit, as shown in Figure 1, was used. Students were asked to turn on the DC power supply and set the source voltage to $2 \mathrm{~V}$. As with the DMM, the power supply leads were 
also color coded for ease of usage. The red measurement lead was connected to the positive terminal of the power supply and the black measurement lead was connected to the negative terminal of the power supply. First, students were asked to measure the source voltage using the voltmeter. To take advantage of the set color coding, students were asked to connect the red lead (plus) of the voltmeter to the red lead of the power supply and the black lead (minus) of the voltmeter to the black lead of the power supply. Students were asked to adjust the voltage to get as close as to $2 \mathrm{~V}$ as possible. In addition, students were asked to observe, what would happen if the leads labeled 'plus' and 'minus' were interchanged, when making measurement. Voltage values can be positive or negative polarity depending on how a particular measurement is made. This concept is important to understand and students were asked to comprehend this concept via multiple measurements across the same circuit element. Then, students were asked to identify the series circuit and connect the 2V DC source across the series circuit. A circuit diagram, as shown in Figure 3, was provided to aid the understanding of the planned measurements.

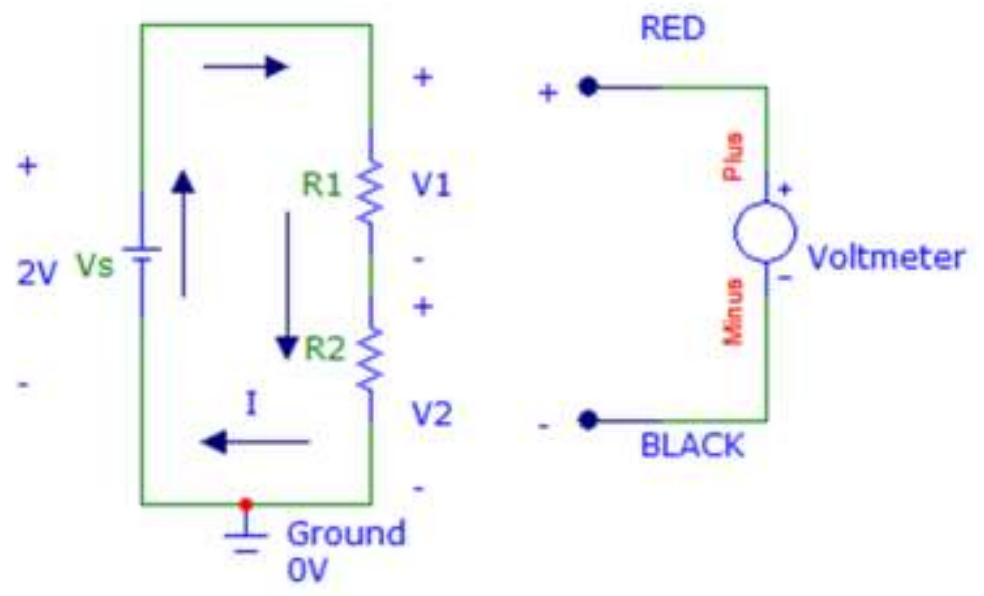

Figure 3: Circuit aid used explain voltage measurements for the series resistor circuits.

Students were asked to measure the voltage across each resistor taking care of the polarity of the connections. As students took measurements, they were asked to apply Ohm's law to calculate the current flowing through that resistor. In addition, through measurements, students were asked to verify:

- The sum of measured voltages across the resistors (V1 + V2) must equal the supply voltage (Vs) value of $2 \mathrm{~V}$ (Figure 3). This is the basic understanding of the important Kirchhof's Voltage Law (KVL).

- The voltage across a resistor is directly proportional to its resistance value.

- The current flowing through the series connected resistors must be same.

The next laboratory exercise delved into the measurement of current in a parallel connected resistor circuit. Students were asked to set the DMM to the ammeter setting. Again, color coding was used to identify the positive (red) and the negative (black) terminals of the ammeter. Measuring current is a bit a tricky since the ammeter needs to be placed in the path of the current. This task requires breaking the circuit and placing the ammeter in the path of the current. This portion of the lab took the longest time. In addition, effort was made to show the current measuring process multiple times so that the technique would sink in. Visual aids, as 
shown in Figure 4, were provided, which helped students understand the process of connecting an ammeter.
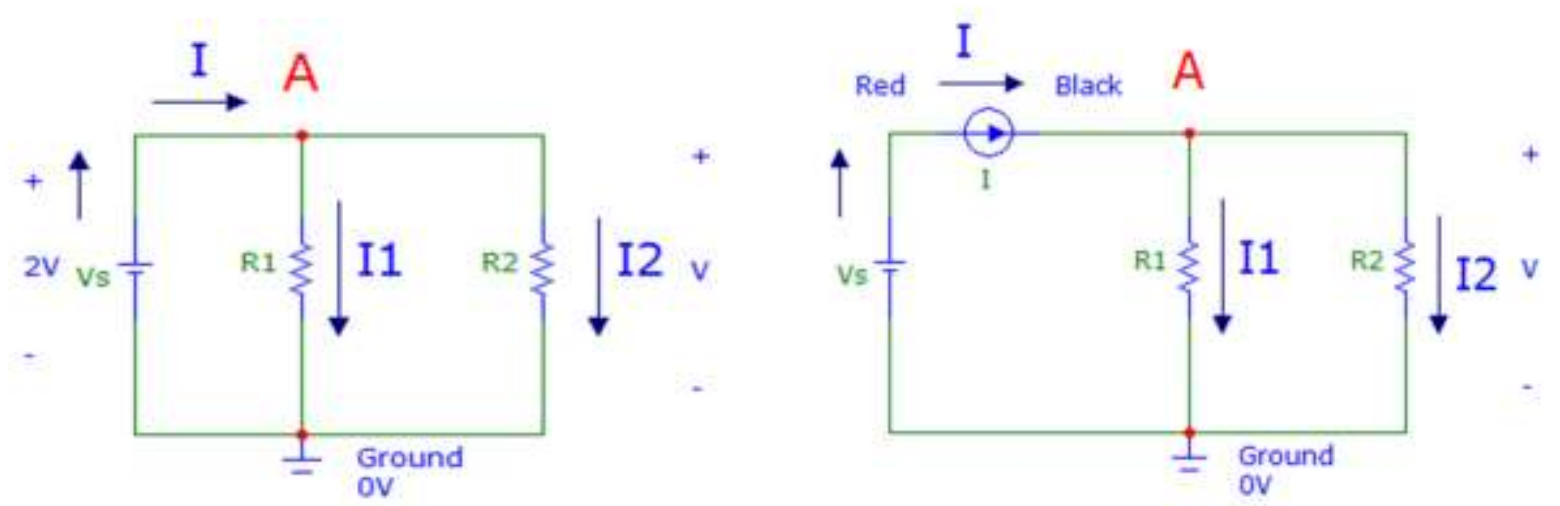

Figure 4: Circuit aid used to explain the procedure used to connect an ammeter to measure current 'I'. Using this information students were challenged to figure out the process to measure 'I1' and ' $\mathrm{I} 2$ '

Students were asked to observe what would happen if the leads labeled 'plus' and 'minus', of the ammeter, are interchanged. Current can be positive or negative depending on how measurements are made, which in mentions the direction of current flow. Students were asked to measure the source current, as shown in Figure 4, and the current through each resistor taking care of the correct method to connect the ammeter. As students took measurements, they were asked to apply Ohm's law to calculate the voltage across each resistor. In addition, through measurements, students were asked to verify:

- The sum of the measured currents through the resistors $(\mathrm{I} 1+\mathrm{I} 2)$ must equal to the measured source current (I) (Figure 4). This is the basic understanding of the important Kirchhof's Current Law (KCL)

- The current through a resistor is inversely proportional to its resistance value.

- The voltage across parallel connected resistors must be same.

Figure 5 shows examples of students working on the measurement exercises. As students finished the assigned measurements exercises, they were asked to complete the Computer Engineering learning module [3, 4], in which they answered the following questions:

- How unsigned (positive) decimal integers are represented, in binary, in computers?

- How signed (positive and negative) decimal integers are represented, in binary, in computers? 

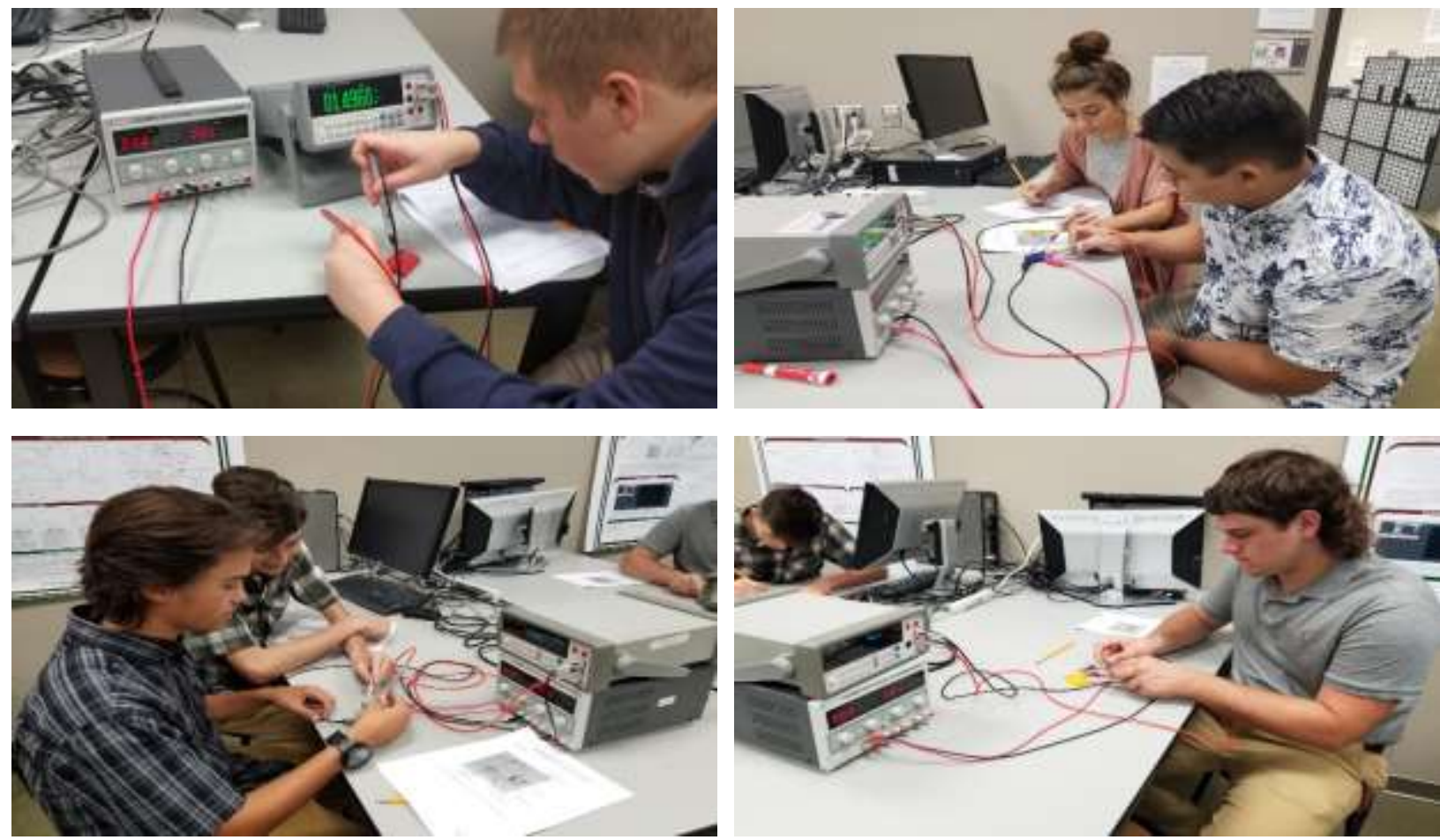

Figure 5: Students working on the electrical parameters measurement laboratory exercises.
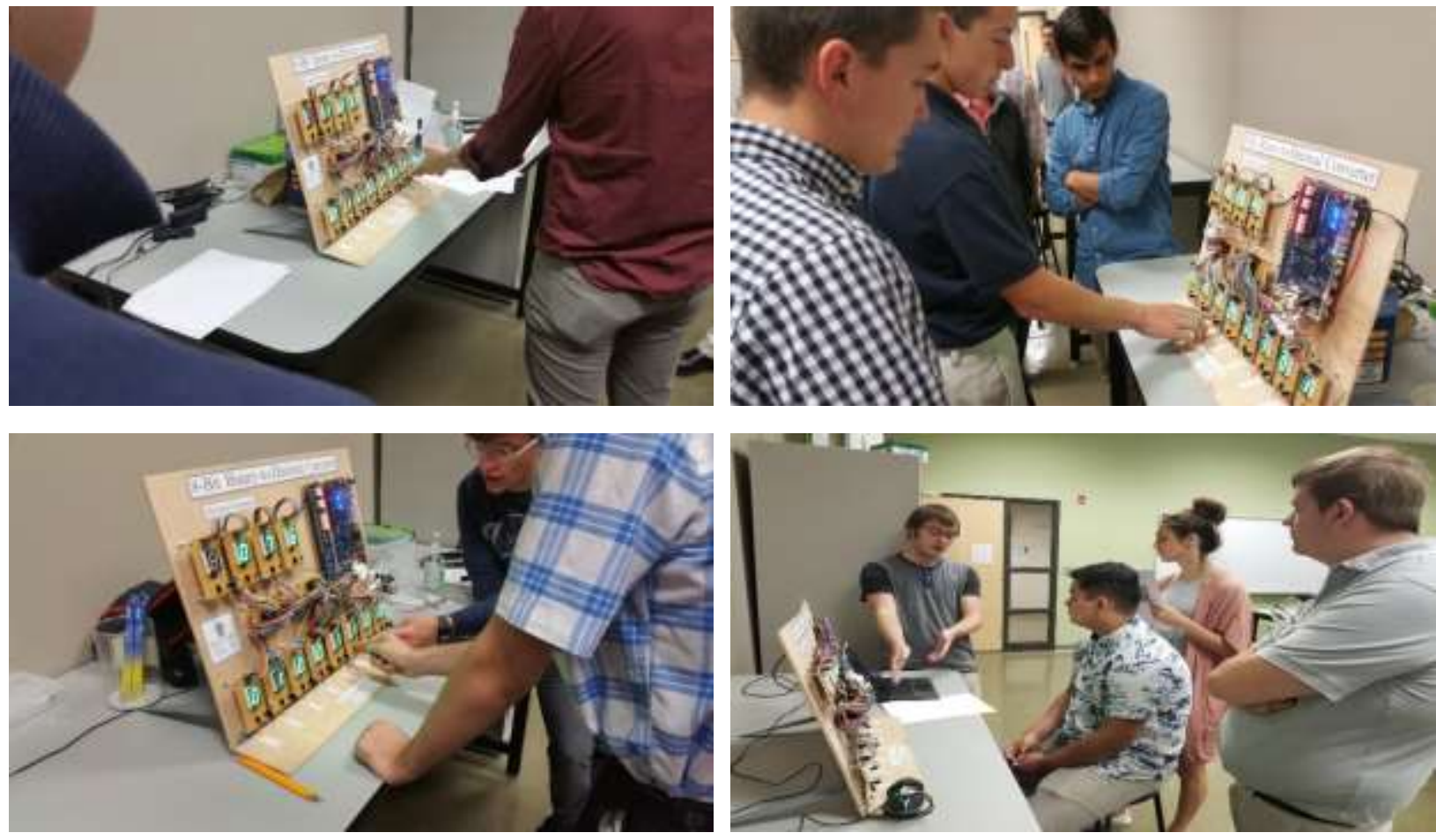

Figure 6: Students using the B-To-D Emulator to practice converting decimal integers into binary equivalent representation. 
The B-To-D emulator has been successfully demonstrated at numerous events and helped many K-12 students understand the decimal to binary conversion process via an interactive tool $[3,4]$. Figure 6 shows examples of students using the emulator to learn Decimal to Binary conversion. In addition, students tried their skill in generating electrical power, using the inhouse built manual bike-power generator. This fun and physically challenging exercise gives students an opportunity to understand the power generation requirements for different kinds of load lamps, ranging from incandescent bulbs, which require more power to operate, to CFC and LED bulbs, which require less power to operate. Figure 7 shows examples of students trying their skill on generating power.
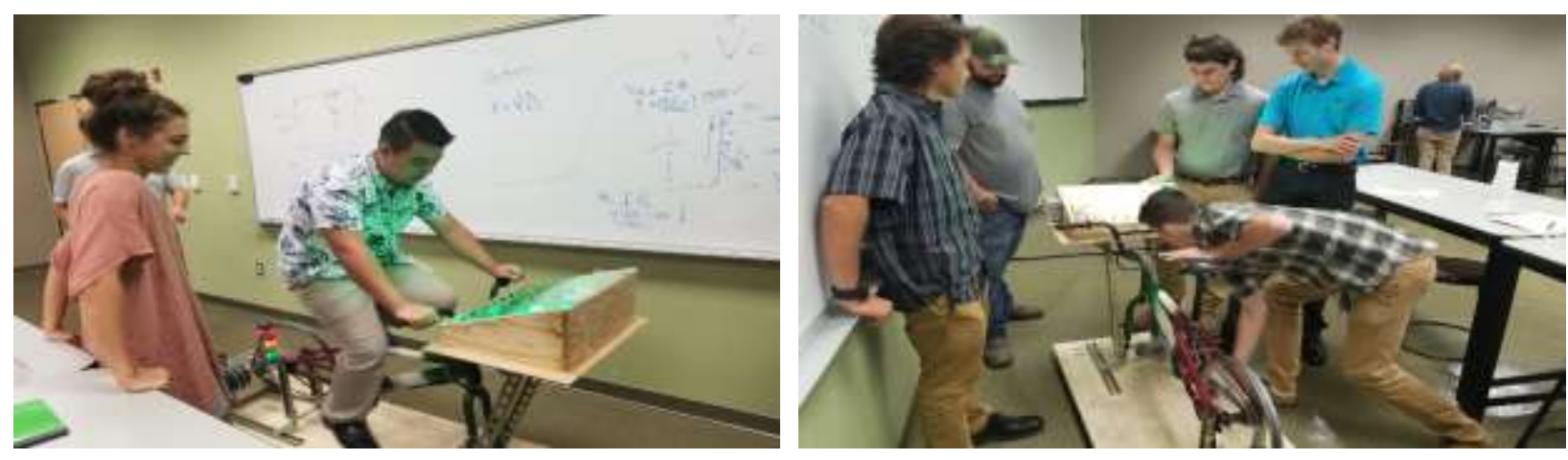

Figure 7: Students trying their skill in generating power.

\section{Survey Results:}

21 students participated in the laboratory exercise. Even though, the lab has been implemented for more students, in the past, only 21 students conducted the survey. Students were asked to respond to several statements (Strongly Agree to Strongly Disagree) related to the covered laboratory components. Figures 8-10 show the results of the conducted survey. The figures also show a brief discussion and interpretation of the results. The survey results show an overall positive and enjoyable learning experience for the participants. Answers to open-ended questions yielded a desire to learn more about the covered concepts. Though many participants have chosen an alternate engineering career path, students were eager to learn basic Electrical and Computer Engineering concepts.

\section{Conclusion and Future Work}

Even though the laboratory was a successful endeavor, there is room for improvement. Given an opportunity to increase the duration of the laboratory and to reduce the number of students, in a session, deeper learning can be achieved. This aspect will be explored in future laboratory sessions. Furthermore, the laboratory exercise will be expanded to include additional components that explore the mentioned electrical engineering concepts in more detail. Currently, the laboratory sessions are held on university campus. K-12 students are required to attend the sessions on university campus. An important future endeavor is to make the entire laboratory portable. This resource will allow sessions to be held at K-12 schools. Past experience has shown that some of the sessions could not be scheduled owing to time conflicts and transportation issues. Moreover, the entire laboratory took about two hours to finish, which worked well within the available schedule of participants. The laboratory exercises concentrate on analysis of circuits. A design component was not included. Future work will concentrate on incorporating 
design component/s, which will most likely increase the duration of the laboratory and will probably work best for groups that can fit the entire laboratory exercise into their schedule.

\begin{tabular}{|c|c|c|}
\hline \multirow{5}{*}{ Comment } & Strongly Agree & \multirow{5}{*}{ Discussion } \\
\hline & Agree & \\
\hline & Neutral & \\
\hline & Disagree & \\
\hline & Strongly Disagree & \\
\hline $\begin{array}{l}\text { I found the lab to be } \\
\text { an interesting } \\
\text { experience }\end{array}$ & & $\begin{array}{l}\text { Most students found the lab to be } \\
\text { an interesting learning experience. }\end{array}$ \\
\hline $\begin{array}{l}\text { I can easily use the } \\
\text { ohmmeter to } \\
\text { measure resistance }\end{array}$ & & $\begin{array}{l}\text { Most students found it easy to use } \\
\text { an ohmmeter to measure } \\
\text { resistance. }\end{array}$ \\
\hline $\begin{array}{l}\text { I can easily use the } \\
\text { voltmeter to } \\
\text { measure voltage }\end{array}$ & & $\begin{array}{l}\text { Most students found it easy to use } \\
\text { a voltmeter to measure voltage. } \\
\text { The operation is similar to using } \\
\text { an ohmmeter. }\end{array}$ \\
\hline $\begin{array}{l}\text { I can easily use the } \\
\text { ammeter to measure } \\
\text { the current }\end{array}$ & & $\begin{array}{l}\text { Only a few students found it easy } \\
\text { to use an ammeter to measure } \\
\text { current, which is tricky since the } \\
\text { ammeter needs to be placed in the } \\
\text { path of the current flow. }\end{array}$ \\
\hline $\begin{array}{l}\text { I understand how } \\
\text { the overall } \\
\text { resistance changes } \\
\text { when the resistors } \\
\text { are connected in } \\
\text { series }\end{array}$ & & $\begin{array}{l}\text { Most students were able to } \\
\text { understand via measurements that } \\
\text { the overall resistance increases, } \\
\text { when resistors are connected in } \\
\text { series. }\end{array}$ \\
\hline
\end{tabular}

Figure 8: Results of the Survey and Discussion 


\begin{tabular}{|c|c|c|}
\hline \multirow{5}{*}{ Comment } & Strongly Agree & \multirow{5}{*}{ Discussion } \\
\hline & Agree & \\
\hline & Neutral & \\
\hline & Disagree & \\
\hline & Strongly Disagree & \\
\hline $\begin{array}{l}\text { I understand how } \\
\text { the overall } \\
\text { resistance changes } \\
\text { when the resistors } \\
\text { are connected in } \\
\text { parallel }\end{array}$ & & $\begin{array}{l}\text { Most students were able to } \\
\text { understand via measurements that } \\
\text { the overall resistance decreases, } \\
\text { when resistors are connected in } \\
\text { parallel. }\end{array}$ \\
\hline $\begin{array}{l}\text { I understand the } \\
\text { concept of KVL }\end{array}$ & & $\begin{array}{l}\text { The concept of KVL was difficult } \\
\text { to understand for some students. } \\
\text { Further experimentation, more } \\
\text { measurements, and an on-depth } \\
\text { discussion might help students } \\
\text { better understand the concept. }\end{array}$ \\
\hline $\begin{array}{l}\text { I understand the } \\
\text { concept of KCL }\end{array}$ & & $\begin{array}{l}\text { The concept of KCL was difficult } \\
\text { to understand for many students. } \\
\text { Further experimentation, more } \\
\text { measurements, and an on-depth } \\
\text { discussion might help students } \\
\text { better understand the concept. }\end{array}$ \\
\hline $\begin{array}{l}\text { I found working in } \\
\text { groups better than } \\
\text { working alone }\end{array}$ & & $\begin{array}{l}\text { Most students found working in } \\
\text { groups. Though, owing to limited } \\
\text { available resources, most groups } \\
\text { were made up of } 2-3 \text { students. } \\
\text { Larger group sizes can lead to } \\
\text { reduced learning. }\end{array}$ \\
\hline $\begin{array}{l}\text { I found the duration } \\
\text { of the lab to ideal }\end{array}$ & & $\begin{array}{l}\text { Most students found the duration } \\
\text { of the lab suitable for } \\
\text { understanding the covered } \\
\text { concept. }\end{array}$ \\
\hline
\end{tabular}

Figure 9: Results of the Survey and Discussion (Contd.) 


\begin{tabular}{|c|c|c|}
\hline \multirow{5}{*}{ Comment } & Strongly Agree & \multirow{5}{*}{ Discussion } \\
\hline & Agree & \\
\hline & Neutral & \\
\hline & Disagree & \\
\hline & Strongly Disagree & \\
\hline $\begin{array}{l}\text { I found the } \\
\text { difficulty level of } \\
\text { the lab to be } \\
\text { reasonable }\end{array}$ & & $\begin{array}{l}\text { Many students were able to } \\
\text { comprehend most of the covered } \\
\text { concepts. But, some students had } \\
\text { difficulty understanding some of } \\
\text { the concepts as mentioned above. }\end{array}$ \\
\hline $\begin{array}{l}\text { At the end of the } \\
\text { lab, I am more } \\
\text { curious about } \\
\text { Electrical } \\
\text { Engineering }\end{array}$ & & $\begin{array}{l}\text { Not every participant was } \\
\text { interested in pursuing a career in } \\
\text { Electrical Engineering. Based on } \\
\text { an asked open-ended question, } \\
\text { many student had already chosen } \\
\text { a different career path other than } \\
\text { Electrical Engineering. }\end{array}$ \\
\hline $\begin{array}{l}\text { I found the B-To-D } \\
\text { converter a useful } \\
\text { tool to understand } \\
\text { decimal to binary } \\
\text { conversions }\end{array}$ & & $\begin{array}{l}\text { The very successful tool has yet } \\
\text { again proved effective in teaching } \\
\text { students the technique to convert } \\
\text { decimal numbers to binary }\end{array}$ \\
\hline $\begin{array}{l}\text { I understand how } \\
\text { decimal numbers } \\
\text { are converted into } \\
\text { binary }\end{array}$ & & $\begin{array}{l}\text { Most students were able to easily } \\
\text { understand the process of } \\
\text { converting decimal to binary } \\
\text { using the tool. Though, some } \\
\text { more practice, with the tool, may } \\
\text { been needed to nail the technique }\end{array}$ \\
\hline $\begin{array}{l}\text { I understand how } \\
\text { negative numbers } \\
\text { are represented in } \\
\text { binary using } 2 \mathrm{~s} \\
\text { complement method }\end{array}$ & & $\begin{array}{l}\text { While understanding the } \\
\text { conversion of positive numbers, } \\
\text { into binary, is relatively easy, the } \\
\text { concept of converting negative } \\
\text { numbers into binary was a bit } \\
\text { tricky for some to understand. }\end{array}$ \\
\hline
\end{tabular}

Figure 10: Results of the Survey and Discussion (Contd.)

Future work will, also, concentrate on expanding the implemented laboratory exercises, implementing the sessions for middle and upper-elementary grade students in a more formal setting, which will include feedback in the form of conducted survey. 


\section{References}

1. ELENCO: Learn By Doing Webpage, "SNAP Circuits: Experiments Toys," (Accessed January 27, 2017). Available: https://www.elenco.com/brand/snap-circuits/

2. GO-CAPS webpage, "Greater Ozarks Centers for Advanced Professional Studies," (Accessed March 15, 2018). Available: https://gocaps.yourcapsnetwork.org/

3. R. Dua, "Interactive Digital Logic Laboratory for K-12 Students (Work in Progress)," 2017 ASEE Annual Conference \& Exposition, Columbus, OH, USA

4. N. Kelly, K. Brown, R. Dua, "Work-In-Progress Interactive Digital Logic Laboratory for Kids: Decimal-To-Binary Conversion Emulator - An Experiential Learning Project," 2015 ASEE Zone III Conference student paper competition winner. Springfield, MO, USA 